\title{
Relationships between Adolescents' and Parents' Values and Parents' Answering Behaviour
}

\author{
Ferran Casas, Germà Coenders, Cristina Figuer, Mònica González, \\ and Sara Malo ${ }^{1}$
}

\begin{abstract}
In this paper we set out a confirmatory factor analysis model relating the values adolescents and their parents aspire to for the child's future. We approach a problem when collecting parents' answers and analysing paired data from parents and their child: the fact that in some families only one parent answers, while in others both meet to answer together. In order to account for differences between one-parent and two-parent responses we follow a multiple group structural equation modelling approach.

Some significant differences emerged between the two and one answering parent groups. We observed only weak relationships between parents' and children's values.
\end{abstract}

\section{Introduction}

A historical examination of values suggests that values change from one generation to another (Alwin, 1990). Social change, whether it comes about by immigration, economic changes, war, or new technology, routinely invalidates the experience of the older generation (Skolnick, 1988). Even traditional research showed that mothers' and fathers' values transmitted to children are not always the same (Kohn, 1983), and that experiences, values, and perceptions within the family are much less shared than was once presumed. Moreover, parents may often condone intergenerational change or actively foster differences between their own socialisation attainments and those of their children (Goodnow, 1994).

\footnotetext{
${ }^{1}$ Quality of Life Research Institute, Faculty of Economics, University of Girona, Campus Montilivi, 17071 Girona (Spain).germa.coenders@udg.edu
} 
Although a relationship between parents' personal values and parents' values oriented towards the raising of their own children (educational values, according to some authors) has often been identified in the scientific literature, research has often concluded that it is very difficult to find empirical evidence to demonstrate the influence of parents' values on children's values - traditionally, correlations found have often been very modest and lower than expected (Hess \& Torney, 1965; Connell, 1972; Thomas \& Stankiewicz, 1974). In fact, according to coconstructionist (Lawrence \& Valsiner, 1993) and interpretative perspectives (Gaskins, Miller, \& Corsaro, 1992) the child's cognitive processing of parental messages ensures that what the child internalises will be an innovative interpretation rather than a direct copy of the parents' message. Interactions with peers and friends also provide sources of knowledge, values and skills that are different from those provided by parents (Hartrup, 1996). And, of course, audiovisual media also have their influence (del Río, Álvarez \& del Río, 2004).

Taking into account all of these considerations, it seems that any research should expect to identify an existing but low correlation between parents' and children's values. The issue of how differences, as well as similarities, arise between children and their parents in values is at present considered central to a theory of socialisation. What is believed to be still missing from the literature is an account of whose values prevail in the socialisation process when different values are observed and experienced in different contexts and interpersonal relationships (Kuczynski, Marshall \& Schell, 1997).

A particular case of comparison of values adopted by parents and children is that of values aspired to - values considered salient to the child's future. According to previous research, during adolescence some low but significant correlations can be observed between parents and their children in relation to salient values for the children's future (Coenders, Casas et al., 2005; Casas, Figuer et al., 2004).

A frequent procedure used to relate the answers of parents and their own children is to send a questionnaire to the parents in a sealed envelope, while the child's questionnaire is administered at school. When the purpose is to identify discrepancies between the father's and the mother's answers, as shown in Mikelson (2008), separated questionnaires must be administered. When this is not a goal, for obvious, practical reasons it is common to send only one questionnaire to each household and keep some record of who answers. Having answers from both parents together has positive aspects, including that they may be more reliable in terms of aspects observed in a child's behaviour, because the two observers must negotiate a single answer. However, this favourable effect on measurement quality may be reversed when we aim to analyse perceptions or evaluations which are not related to the child's behaviour like, for instance, values.

In samples of Spanish households, the overall response rate provided by parents (both together or only father or mother) has usually been relatively high between $39 \%$ and $49.8 \%$ in 4 different data collections in Spain (Casas, Buxarrais 
et al., 2004; Casas, Figuer et al., 2004; Coenders, Casas, et al., 2005; Casas, Figuer et al., 2007; Casas, Coenders et al., 2008). However, for the usual analysis of answers given by only one parent, the parents' sample becomes reduced to between $25.5 \%$ and $38.4 \%$ of children's sample, because of the important proportion of families in which the two parents tend to answer together the questionnaire. Moreover, an unequal gender distribution is observed between mothers answering alone and fathers doing so (a mean of $46.9 \%$ for the former and a $18.7 \%$ for the latter in these same 4 data collections).

When both parents answer together, the validity of the answers about values they aspire to for their own child's future may remain unclear, because the two evaluations may be rather different (as shown in Mikelson, 2008, results) as the father and the mother may aspire to very different values for their own son's or daughter's future.

Data collections in Spain between 1999 and 2008 suggest the possibility that the patterns of answers in those families where parents answer a questionnaire jointly are clearly not the "mean" of the answers of fathers answering alone and mothers answering alone. This raises a complicated challenge, which becomes a kind of methodological paradox: when we analyse only the sub-samples of parents answering alone, we may be increasing non-response bias, because we may in fact be excluding families with a specific answering style. However, if we do not delete these families' answers from our analysis, the data may be non-comparable.

The answers given by one or two parents may not only differ because of methodological reasons. Whether parents engage in tasks regarding their children, such as answering a questionnaire coming from school, together or alone may be related to the parents' interpersonal relationship styles and to their parenting strategies. Thus, it can also have an impact of their relationships with their children regarding aspects such as intergenerational value transmission, for instance.

In this paper a model is set forth relating the values the child aspires to for his/her future to the values parents aspire to for the child's future.

The main contribution of this article is a methodological one. Data were analysed by means of multiple group structural equation models -SEM- to ensure that the data of one parent and two parents answering the questionnaire were comparable. This makes it possible to keep both groups in the sample and to test for differences between them. In addition, in order to ensure unbiasedness of both point estimates and statistical tests, robust standard errors for complex samples and non-normal data were used, and missing data were handled by means of multiple imputation. 


\section{Method}

\subsection{Sample selection}

We randomly selected a sample of 7 schools within the province of Girona, a region in the north east of Spain. In each school, we reported our aims to the principal and to the parents' association, and proceeded in accordance with standard ethical guidelines for questionnaire administration to children.

When participation of the school in our study had been agreed, we randomly selected a number of classes until we fulfilled a quota for each age group from each school, and we asked the class teacher for cooperation. The children were then asked for their own cooperation and informed that data would be treated confidentially. The questionnaires were administered to the group in their usual classroom. One of their teachers and one or two researchers were present during the administration and clarified any questions that arose. The session usually lasted about one hour for the youngest and about 35 - 40 minutes for the oldest.

At the end of the session, we gave each child a letter and a questionnaire for their parents. They were asked to return it to the teacher in a sealed envelope within approximately one week. The questionnaire could be answered by either parent or by both parents together, and a record was kept of that important variable. Each parent's questionnaire was coded, so that it could be paired with their child's. In their questionnaire, parents were asked to answer with only the child who had answered our school questionnaire in mind.

Children whose parents answered the questionnaire, either alone $(n=323)$ or both together $(n=146)$ were selected $(n=469$ out of an initial 1,276). The rest constituted parent non-responses $(n=798)$, or responses given by tutors $(n=2)$ or other family members $(n=7)$. By age and gender, $14.3 \%$ were aged $12,23.0 \%$ aged $13,27.3 \%$ aged $14,20.3 \%$ aged $15,13.6 \%$ aged 16 and $1.5 \%$ aged $17 ; 38.4 \%$ were boys and $61.6 \%$ were girls.

\subsection{Measurement instruments}

The questionnaires were in Spanish and Catalan and had already been tested in previous studies (Coenders, Casas et al., 2005; Casas, Figuer et al., 2004; Casas, González et al., 2004). In the region where the questionnaires were administered, both languages are official and all children (with the exception of recent immigrants) speak them both fluently. However, that is not the case for all parents, so they were able to choose the language with which they felt more comfortable.

The children's questionnaire included a specific battery of items in order to evaluate salient values for their own future and were asked to what extent they would like to be appreciated for some specific values when they reach the age of 
21. We have used this technique in previous research in order to identify differences in value structures between parents and children (Casas, Buxarrais et al., 2004; Coenders, Casas et al., 2005). For the present study, we designed a closed set of items with twenty-three values: intelligence, technical skills (practical skills), skills with people, computer knowledge, profession, family, sensitivity, niceness (friendliness), money, power, world knowledge, self image, responsibility, solidarity, tolerance, good manners, joie de vivre, creativity, work capacity, faith or spirituality, perseverance (constancy), personality and kindness; all were measured over a 0 to 10 scale, 0 meaning not at all and 10 very much. Intermediate scale points were unlabelled.

A set of equivalent items was included in the parents' questionnaire. In this case, they were asked to indicate to what extent they would like their child to be appreciated by other people for the same 23 values when the child reached the age of 21.

\subsection{Exploratory data analyses}

The percentage of missing values was low, at 3\%, and did not concentrate on any particular variable (minimum was $1.3 \%$ and maximum was 5.5\%). However, the listwise sample size would have been reduced from $n=469$ to $n=244$. Table 1 shows some descriptive statistics and the number of valid cases for each variable.

Exploratory factor analyses carried out by maximum likelihood with Oblimin rotation and a careful analysis of correlation matrices revealed five interpretable value dimensions. The composition of the dimensions could vary somewhat between parents and children but can be described as:

1) Values related to abilities and knowledge (intelligence, technical/practical skills, skills with people, computer knowledge, profession).

2) Materialistic values (money, power, own image).

3) Relationship values (sensitivity, solidarity, tolerance, good manners).

4) Values related to extraversion and personality (niceness/friendliness, joie de vivre, personality, kindness).

5) Values related to effort (responsibility, work capacity, perseverance/constancy). 
Table 1: Univariate descriptive statistics.

\begin{tabular}{|c|c|c|c|c|c|}
\hline & valid $n$ & nean & St dev & skewness $^{\mathrm{a}}$ & kurt. $^{\mathrm{b}}$ \\
\hline VAL_INT: Value: intelligence & 465 & 7.45 & 2.24 & -1.00 & 1.07 \\
\hline VAL_TECH: Value: tech. skills (practical skills) & 461 & 7.39 & 2.10 & -.99 & 1.41 \\
\hline VAL_PEOP: Value: skills with people & 461 & 7.86 & 2.01 & -1.22 & 1.67 \\
\hline VAL_COMP: Value: computer knowledge & 462 & 6.30 & 2.83 & -.61 & -.38 \\
\hline VAL_PROF: Value: profession & 462 & 8.04 & 2.10 & -1.30 & 1.52 \\
\hline VAL_FAM: Value: family & 462 & 8.05 & 2.21 & -1.20 & 1.12 \\
\hline VAL_SEN: Value: sensitivity & 459 & 7.74 & 2.37 & -1.27 & 1.41 \\
\hline VAL_FRIE: Value: niceness (friendliness) & 461 & 8.43 & 2.05 & -1.86 & 4.00 \\
\hline VAL_MON: Value: money & 460 & 4.77 & 3.25 & .02 & -1.08 \\
\hline VAL_POW: Value: power & 455 & 4.87 & 3.26 & -.04 & -1.11 \\
\hline VAL_WORL: Value: world knowledge & 460 & 6.60 & 2.56 & -.64 & -.29 \\
\hline VAL_IMA: Value: self image & 459 & 6.82 & 2.89 & -.77 & -.21 \\
\hline VAL_RESP: Value: responsibility & 460 & 7.85 & 2.19 & -1.21 & 1.35 \\
\hline VAL_SOL: Value: solidarity & 454 & 7.42 & 2.40 & -1.07 & .87 \\
\hline VAL_TOL: Value: tolerance & 453 & 7.17 & 2.39 & -1.01 & .93 \\
\hline VAL_MAN: Value: good manners & 458 & 7.85 & 2.17 & -1.40 & 2.14 \\
\hline VAL_JOIE: Value: joie de vivre & 461 & 8.40 & 1.96 & -1.75 & 3.77 \\
\hline VAL_CREA: Value: creativity & 455 & 7.37 & 2.19 & -.99 & 1.02 \\
\hline VAL_CAPT: Value: work capacity & 457 & 7.77 & 2.13 & -1.45 & 2.65 \\
\hline VAL_FAIT: Value: faith or spirituality & 457 & 5.57 & 3.24 & -.35 & -1.00 \\
\hline VAL_CONS: Value: perseverance (constancy) & 457 & 7.06 & 2.23 & -.85 & .70 \\
\hline VAL_PERS: Value: personality & 461 & 8.57 & 1.74 & -1.59 & 2.89 \\
\hline VAL_KIND: Value: kindness & 463 & 8.52 & 1.84 & -1.76 & 3.83 \\
\hline P_V_INT: Parents value: intelligence & 456 & 8.02 & 1.92 & -.99 & 1.19 \\
\hline P_V_TECH: Parents value: tech. (practical) skills & 449 & 7.79 & 1.88 & -.92 & 1.43 \\
\hline P_V_PEOP: Parents value: skills with people & 452 & 8.30 & 1.66 & -.97 & .73 \\
\hline P_V_COMP: Parents value: comp. knowledge & 446 & 7.06 & 2.34 & -.80 & .51 \\
\hline P_V_PROF: Parents value: profession & 453 & 8.27 & 1.92 & -1.51 & 2.74 \\
\hline P_V_FAM: Parents value: family & 456 & 8.72 & 1.78 & -1.97 & 4.93 \\
\hline P_V_SEN: Parents value: sensitivity & 458 & 8.53 & 1.80 & -1.88 & 4.85 \\
\hline P_V_FRIE: Parents value: niceness (friendliness) & 452 & 8.38 & 1.85 & -1.61 & 3.40 \\
\hline P_V_MON: Parents value: money & 453 & 4.63 & 3.08 & -.07 & -.94 \\
\hline P_V_POW: Parents value: power & 450 & 4.73 & 3.15 & -.027 & -1.00 \\
\hline P_V_WORL: Parents value: world knowledge & 452 & 7.59 & 2.11 & -1.14 & 1.65 \\
\hline P_V_IMA: Parents value: self image & 453 & 6.81 & 2.53 & -.85 & .47 \\
\hline P_V_RESP: Parents value: responsibility & 457 & 8.86 & 1.55 & -2.22 & 6.61 \\
\hline P_V_SOL: Parents value: solidarity & 455 & 8.84 & 1.57 & -2.15 & 6.33 \\
\hline P_V_TOL: Parents value: tolerance & 456 & 8.62 & 1.68 & -1.73 & 3.97 \\
\hline P_V_MAN: Parents value: good manners & 455 & 8.74 & 1.62 & -1.80 & 4.31 \\
\hline P_V_JOIE: Parents value: joie de vivre & 454 & 9.11 & 1.49 & -2.69 & 9.67 \\
\hline P_V_CREA: Parents value: creativity & 452 & 8.47 & 1.71 & -1.55 & 3.27 \\
\hline P_V_CAPT: Parents value: work capacity & 454 & 8.67 & 1.58 & -1.78 & 4.40 \\
\hline P_V_FAIT: Parents value: faith or spirituality & 445 & 6.54 & 2.83 & -.65 & -.30 \\
\hline P_V_CONS: Parents val.: perseverance(constancy) & 456 & 8.44 & 1.78 & -1.73 & 4.06 \\
\hline P_V_PERS: Parents value: personality & 454 & 8.92 & 1.45 & -1.82 & 4.37 \\
\hline P_V_KIND: Parents value: Kindness & 456 & 8.82 & 1.54 & -1.61 & 3.27 \\
\hline
\end{tabular}

${ }^{\text {a }}$ Significant at $\alpha=5 \%$ if larger than 0.23 in absolute value

${ }^{\mathrm{b}}$ Significant at $\alpha=5 \%$ if larger than 0.46 in absolute value 


\subsection{Comparability of subgroups}

As has been argued, the joint response to a questionnaire by two people (both parents) may have advantages and disadvantages and may involve distinct response behaviour. We therefore need to ensure that these joint responses are comparable to those given by one parent individually. Besides methodological implications related to different measurement quality in both groups, families in which both parents tend to share tasks involving their children (such as answering a questionnaire about them) may differ in a number of ways from families in which this is not the case, thus leading to differences in factor means and factor correlations. Our exploratory data analyses in fact revealed that the responses of parents answering together were somewhat different from those of one parent answering alone and from the average computed from fathers' and mothers' responses.

Factor invariance - also called measurement invariance, measurement equivalence, factor equivalence, and construct comparability - refers to the extent to which items used in survey-type instruments and the dimensions they measure mean the same thing to members of different groups. It is thus clear that factor invariance is needed before the one- and two-parent responding groups can be compared or combined in a meaningful way, as otherwise, group differences in means or correlations could be attributable to true differences in group distributions or to a different meaning of variables (Little, 1997; Meredith, 1993).

Multiple-group SEM (Jöreskog, 1971; see Bollen, 1989 or Coenders, BatistaFoguet \& Saris, 2005 as introductory manuals) are a standard procedure for testing factor invariance. Under this approach the same SEM, usually a confirmatory factor analysis (CFA) model, is simultaneously fitted to the data of several populations constraining certain parameters to be equal across groups, as explained below.

A first requisite for factor invariance is the so-called configural invariance, defined as the fact that individuals of different groups conceptualise the constructs in the same way (Meredith, 1993; Riordan \& Vandenberg, 1994). Its assessment consists of checking that the same CFA model is appropriate in all groups.

A second requisite is metric invariance, which implies that in addition to configural invariance, all factor loading parameters be constrained to be equal across groups. Thus, not only the items composing each dimension but also the strength of the relationship between items and factors must be constant. Metric invariance is a requisite for cross-group comparison of factor variances, covariances and correlations.

A third requisite is called strong factor invariance (Meredith, 1993). In addition to metric invariance, strong factor invariance requires that measurement intercepts (values of the item corresponding to the zero value of the construct) also be constrained across groups. Strong factor invariance is a prerequisite for comparing factor means. 
Tests of factor invariance involve tests of the aforementioned constraints. A wealth of goodness of fit measures are usually considered for testing constraints in SEM (Bollen \& Long, 1993). Usually researchers are not particularly concerned with exactly fitting model constraints, so that quantitative measures of misfit are preferred to tests of exact fit such as the likelihood ratio $\chi^{2}$ test, which is strongly influenced by parameter values and sample size. Cheung and Rensvold (2002) argue that this later consideration should also hold when testing factor invariance constraints. For the specific purpose of testing invariance constraints, Cheung and Rensvold (2002) run a Monte Carlo experiment of 20 fit indices and conclude that the comparative fit index or CFI (Bentler, 1990) is among the best suited, being hardly influenced by sample size and model parameter values. The authors suggest computing the difference in CFI between two models with and without invariance constraints. If this difference is larger than 0.01 in favour of the less restricted model, then restrictions, and thus invariance, should be rejected.

\subsection{Estimation and testing}

Three important obstacles to obtaining proper inferences in SEM are present in our dataset, namely missing data, non-normality and complex sample design.

Missing data were treated by means of multiple regression imputation (Rubin, 1977, 1987, 1996; Little \& Rubin, 1987, 1989). A simplified variant of the method which is available in SPSS uses a regression model to predict each missing variable from the other variables. This is repeated $\mathrm{m}$ times (e.g. 5 times), by adding different randomly drawn residuals to the regression prediction. The statistical analysis of interest is carried out on each imputed data set (i.e. $m$ times). The point estimate of any parameter is computed as the mean of the $\mathrm{m}$ point estimates. The sampling variance of any parameter estimate takes into account not only sampling variability but also imputation variability across the $\mathrm{m}$ imputed data sets.

From the skewness and kurtosis in Table 1 it can be seen that departures from normality are quite pronounced in our case, so that robust standard errors and test statistics are required. Among these are Yuan and Bentler's T2* (Yuan \& Bentler, 2000) and sandwich standard errors (Arminger \& Sobel, 1990).

The sampling design used in this study is known as cluster sampling. Under this design, cases corresponding to the same cluster (in our case the school) are dependent (students at the same school tend to be more similar than students from different schools) thus violating the independence assumption of standard statistical analysis. Corrections to statistical tests for cluster samples have also been developed in the context of SEM (Muthén \& Satorra, 1995).

All SEM estimations were carried out with the M-PLUS 3.11 program (Muthén \& Muthén, 2004), with test statistics robust to non-normality and cluster samples 
and the multiple imputation option, using $m=5$ data sets obtained with the regression imputation option in SPSS.

\section{Results}

\subsection{One-group model on data from questionnaires answered by only one parent}

A CFA imposing the factor structure described in the exploratory analysis section was first specified separately for parents and children and then for parents and children together treated as separate variables (that is, a model with 10 factors, five for children and five for parents). We used the larger group, in which one parent answered the questionnaire. A process of model modification was carried out with the aim of finding a small group of best indicators for each dimension, which could work well for both parents and children. The final model is depicted in Figure 1. The fit of the model is rather good, the average CFI over the 5 imputed data sets being 0.976 (values above 0.95 are generally considered appropriate). The final indicators for each value dimension, for both parents and children are:

1) KNOWL: Values related to abilities and knowledge, including intelligence and technical skills (practical skills).

2) MATER: Materialistic values, including money and power.

3) RELAT: Relationship values, including tolerance and good manners.

4) PERSO: Values related to extraversion and personality, including joie de vivre and personality.

5) EFFOR: Values related to effort, including perseverance (constancy) and work capacity.

\subsection{Factor invariance tests: multiple group analyses}

In order to test for configural invariance, we fitted the model to data from both the one- and two-parent groups without parameter constraints across groups. The same model seemed to fit the data of both groups quite well (average CFI=0.963). The error variance of the power value of parents was negative and non-significant in the two-parent group and was constrained to 0.001 . 


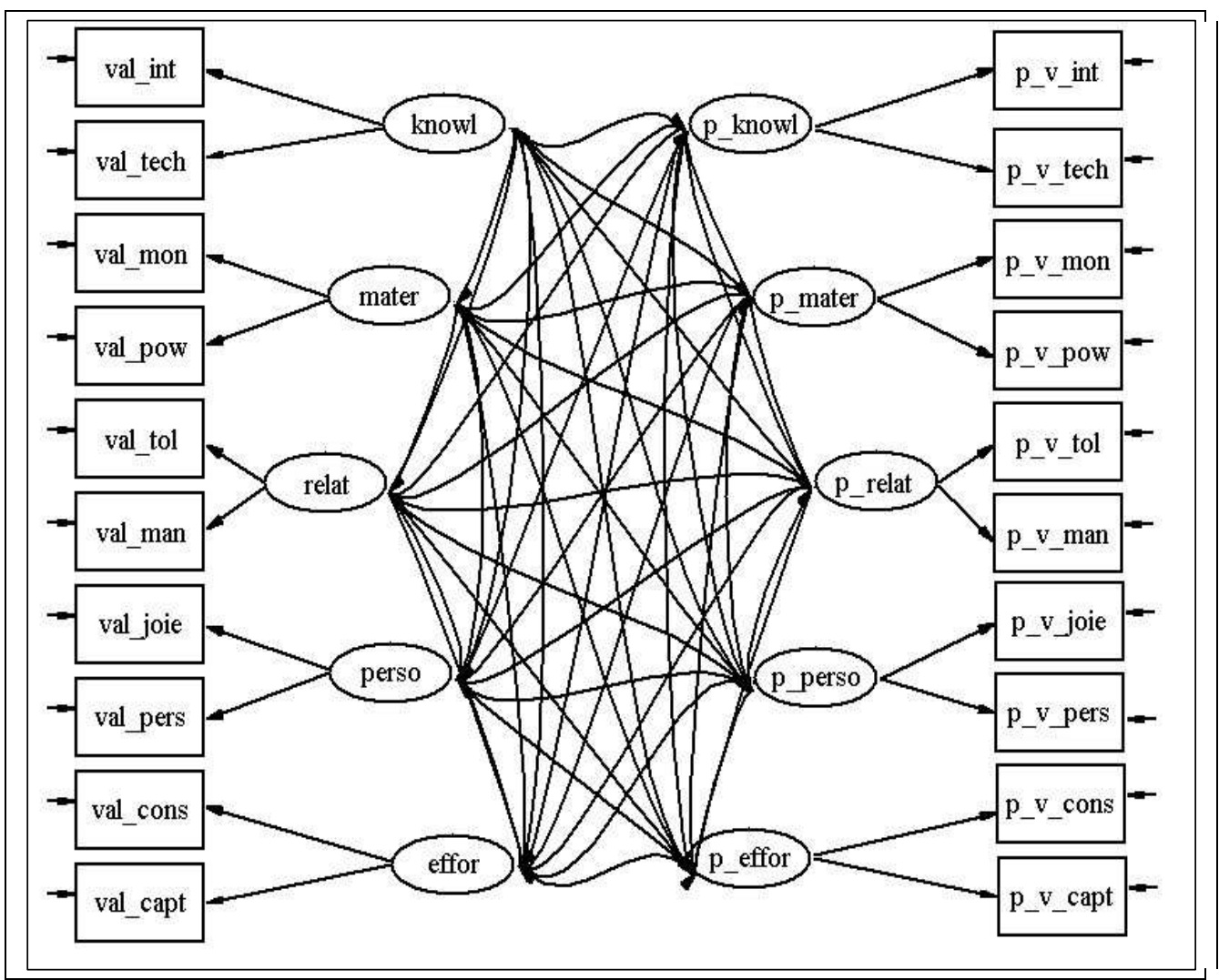

Figure 1: Path diagram of final Confirmatory Factor Analysis (CFA) model for children's and parents' Values.

In order to test for strong factor invariance, we specified equality of all intercepts and loadings across groups. The fit of the model worsened only slightly (average $\mathrm{CFI}=0.960$ ). As the drop in CFI is well below 0.01 , we consider strong factor invariance to approximately hold, as suggested by Cheung \& Rensvold (2002).

The factor variances of the first group (one-parent answers) are set at 1 as reference, and the factor variances of the second group (where both parents answer) are free parameters. Similarly, the factor means of the first group are set at 0 as reference and the factor means of the second group are free parameters. The factor means in the second group are thus mean differences and the fact that the metric invariance assumption is tenable makes it possible to test their statistical significance.

\subsection{Model interpretation and comparison across groups}

Table 2 shows the estimates of the measurement equations in the strong factor invariance model. Only one set of measurement intercepts and loadings is 
necessary, as they are constrained to be equal across groups. However, the percentages of explained variance, sometimes called measurement quality or communalities, do differ.

Table 2: Children's and Parents' values. Measurement equation parameters ${ }^{\mathrm{a}}$.

\begin{tabular}{ccccccc}
\hline & $\begin{array}{c}\text { Loadings } \\
\text { Estimate }\end{array}$ & $\begin{array}{c}\text { Intercepts } \\
\text { t-value }\end{array}$ & $\begin{array}{c}\text { Estimate } \\
\text { t-value }\end{array}$ & $\begin{array}{c}\mathrm{R}^{2} \text { one } \\
\text { parent }\end{array}$ & $\begin{array}{c}\mathrm{R}^{2} \text { both } \\
\text { parents }\end{array}$ \\
\hline VAL_INT & 1.83 & 12.93 & 7.55 & 87.81 & $69.7 \%$ & $60.1 \%$ \\
VAL_TECH & 1.63 & 10.42 & 7.49 & 136.64 & $65.9 \%$ & $47.4 \%$ \\
VAL_MON & 2.87 & 29.86 & 4.79 & 20.31 & $77.6 \%$ & $70.0 \%$ \\
VAL_POW & 3.04 & 19.68 & 4.85 & 16.77 & $87.3 \%$ & $80.6 \%$ \\
VAL_TOL & 1.63 & 11.77 & 7.34 & 48.17 & $52.6 \%$ & $46.3 \%$ \\
VAL_MAN & 1.73 & 10.58 & 8.00 & 55.44 & $69.2 \%$ & $64.8 \%$ \\
VAL_JOIE & 1.44 & 6.58 & 8.46 & 86.80 & $54.6 \%$ & $57.3 \%$ \\
VAL_PERS & 1.25 & 7.87 & 8.63 & 74.01 & $56.4 \%$ & $45.8 \%$ \\
VAL_CONS & 1.56 & 9.20 & 7.08 & 48.92 & $48.2 \%$ & $34.0 \%$ \\
VAL_CAPT & 1.57 & 8.47 & 7.81 & 83.01 & $57.2 \%$ & $32.4 \%$ \\
\hline P_V_INT & 1.33 & 12.87 & 7.98 & 68.90 & $46.9 \%$ & $55.2 \%$ \\
P_V_TECH & 1.59 & 27.85 & 7.73 & 99.85 & $69.3 \%$ & $85.1 \%$ \\
P_V_MON & 2.45 & 11.43 & 4.61 & 48.29 & $65.0 \%$ & $63.0 \%$ \\
P_V_POW & 3.03 & 26.59 & 4.69 & 40.53 & $90.3 \%$ & $100.0 \%$ \\
P_V_TOL & 1.30 & 9.46 & 8.67 & 78.98 & $70.3 \%$ & $59.7 \%$ \\
P_V_MAN & 1.24 & 9.73 & 8.77 & 65.56 & $59.0 \%$ & $76.1 \%$ \\
P_V_JOIE & 1.17 & 6.72 & 9.11 & 137.51 & $65.8 \%$ & $59.3 \%$ \\
P_V_PERS & 1.13 & 5.76 & 8.91 & 78.57 & $62.2 \%$ & $63.4 \%$ \\
P_V_CONS & 1.31 & 10.89 & 8.40 & 236.03 & $55.6 \%$ & $67.1 \%$ \\
P_V_CAPT & 1.07 & 8.43 & 8.66 & 143.39 & $45.6 \%$ & $68.1 \%$ \\
\hline PE_ & & & & \\
\hline
\end{tabular}

${ }^{a}$ Measurement error variances are omitted for the sake of simplicity

Tables 3 and 4 show factor correlations and differences in factor means. On average, correlations are higher in the two-parent group but in general, the signs and significance of the correlations coincide for the two groups. High correlations occur among all children's values and among all parents' values, with only one exception: no correlation is observed between relationship values and materialistic values of parents. On the other hand, few significant correlations are observed between parents' and children's values. Materialistic values (MATER) are significantly related between parents and children in both groups. In the twoparent group, children's materialistic values are negatively and significantly correlated to parents' knowledge values (KNOWL). In the one-parent group, children's extraversion and personality values (PERSO) are negatively correlated to parents' materialistic values. 
Table 3: Children's and Parents' values. Factor correlations.

\begin{tabular}{|c|c|c|c|c|}
\hline \multirow[b]{2}{*}{ factor correlations } & \multicolumn{2}{|c|}{ Group one parent } & \multicolumn{2}{|c|}{ Group both parents } \\
\hline & Estimate & t-value & Estimate & t-value \\
\hline MATER-KNOWL & 0.30 & 5.29 & 0.40 & 3.97 \\
\hline RELAT-KNOWL & 0.47 & 4.57 & 0.77 & 5.78 \\
\hline RELAT-MATER & 0.41 & 6.94 & 0.45 & 4.80 \\
\hline EFFOR-KNOWL & 0.60 & 12.76 & 0.70 & 3.98 \\
\hline EFFOR-MATER & 0.44 & 7.14 & 0.41 & 3.00 \\
\hline EFFOR-RELAT & 0.79 & 11.94 & 0.93 & 3.58 \\
\hline PERSO-KNOWL & 0.52 & 9.36 & 0.73 & 2.87 \\
\hline PERSO-MATER & 0.24 & 2.87 & 0.38 & 3.63 \\
\hline PERSO-RELAT & 0.78 & 12.02 & 0.75 & 2.93 \\
\hline PERSO-EFFOR & 0.65 & 7.80 & 0.91 & 4.18 \\
\hline P_MATER-P_KNOWL & 0.27 & 3.93 & 0.19 & 2.09 \\
\hline P_RELAT-P_KNOWL & 0.46 & 5.38 & 0.55 & 3.04 \\
\hline P_RELAT-P_MATER & 0.01 & 0.16 & 0.13 & 1.25 \\
\hline P_EFFOR-P_KNOWL & 0.61 & 5.33 & 0.64 & 6.41 \\
\hline P_EFFOR-P_MATER & 0.20 & 1.89 & 0.22 & 3.87 \\
\hline P_EFFOR-P_RELAT & 0.65 & 5.51 & 0.95 & 4.69 \\
\hline P_PERSO-P_KNOWL & 0.31 & 4.26 & 0.64 & 3.58 \\
\hline P_PERSO-P_MATER & 0.19 & 6.34 & 0.22 & 3.13 \\
\hline P_PERSO-P_RELAT & 0.65 & 8.34 & 0.98 & 3.09 \\
\hline P_PERSO-P_EFFOR & 0.79 & 8.56 & $1.07^{\mathrm{a}}$ & 5.85 \\
\hline P_KNOWL-KNOWL & 0.05 & 0.75 & -0.02 & -0.21 \\
\hline P_KNOWL-MATER & 0.01 & 0.20 & -0.20 & -3.00 \\
\hline P_KNOWL-RELAT & 0.04 & 0.47 & -0.07 & -0.78 \\
\hline P_KNOWL-EFFOR & 0.02 & 0.32 & 0.09 & 0.80 \\
\hline P_KNOWL-PERSO & -0.02 & -0.16 & -0.01 & -0.06 \\
\hline P_MATER-KNOWL & -0.02 & -0.24 & -0.09 & -1.31 \\
\hline P_MATER-MATER & 0.28 & 7.18 & 0.17 & 2.82 \\
\hline P_MATER-RELAT & -0.02 & -0.27 & -0.07 & -0.77 \\
\hline P_MATER-EFFOR & -0.09 & -1.27 & 0.07 & 0.85 \\
\hline P_MATER-PERSO & -0.11 & -1.99 & -0.02 & -0.20 \\
\hline P_RELAT-KNOWL & 0.03 & 0.35 & -0.13 & -1.65 \\
\hline P_RELAT-MATER & -0.05 & -1.20 & -0.06 & -0.61 \\
\hline P_RELAT-RELAT & -0.10 & -1.13 & -0.07 & -1.26 \\
\hline P_RELAT-EFFOR & 0.06 & 0.77 & -0.01 & -0.04 \\
\hline P_RELAT-PERSO & -0.05 & -0.75 & -0.05 & -0.94 \\
\hline P_EFFOR-KNOWL & -0.05 & -0.63 & 0.00 & 0.02 \\
\hline P_EFFOR-MATER & -0.09 & -1.05 & -0.08 & -0.85 \\
\hline P_EFFOR-RELAT & 0.05 & 0.35 & 0.00 & 0.02 \\
\hline P_EFFOR-EFFOR & 0.05 & 0.65 & 0.08 & 0.48 \\
\hline P_EFFOR-PERSO & -0.07 & -0.62 & 0.08 & 0.89 \\
\hline P_PERSO-KNOWL & -0.08 & -1.63 & -0.08 & -0.93 \\
\hline P_PERSO-MATER & -0.06 & -0.60 & -0.04 & -0.40 \\
\hline P_PERSO-RELAT & 0.07 & 0.48 & -0.01 & -0.08 \\
\hline P_PERSO-EFFOR & 0.04 & 0.39 & -0.09 & -0.77 \\
\hline P PERSO-PERSO & -0.02 & -0.38 & -0.04 & -0.45 \\
\hline
\end{tabular}

${ }^{\mathrm{a}}$ Non-significantly above 1 
Table 4: Children's and Parents' mean values (Variances are omitted). Difference twoparent minus one-parent group.

\begin{tabular}{lcc}
\hline & Estimate & t-value \\
\hline KNOWL & -0.17 & -2.27 \\
MATER & 0.01 & 0.06 \\
RELAT & -0.31 & -2.22 \\
PERSO & -0.16 & -1.10 \\
EFFOR & -0.06 & -1.03 \\
P_KNOWL & 0.11 & 1.04 \\
P_MATER & 0.03 & 0.35 \\
P_RELAT & -0.06 & -0.57 \\
P_PERSO & 0.02 & 0.22 \\
P_EFFOR & 0.09 & 1.10 \\
\hline
\end{tabular}

Some factor means differ across groups. Children of parents who answer together are less likely to want to be appreciated for their abilities and knowledge (KNOWL) and for their relationship (RELAT) values.

\section{Discussion}

When Casas, Figuer et al. (2004) and Coenders, Casas et al (2005) used a shorter list of values aspired to, 3 dimensions emerged: abilities and knowledge, materialistic and relationship, and significant parent-child correlations were obtained for all of them. However, these correlations were very low for the abilities and knowledge and relationship dimensions and attained statistical significance only as a result of the very large samples used in those studies (above $\mathrm{N}=3000$ ).

In this article we have used statistical methods adapted to the characteristics of the data, in order to minimise the possibility that the results are contaminated by data quality problems. CFA models correct for measurement error attenuation bias. Multiple group models account for the heterogeneity of the two-parent responses and thus avoid the non-response bias that would ensue if these responses were omitted from the analysis. Multiple imputation corrects missing data bias and properly accounts for missing data uncertainty. The statistical distribution of the variables and the sample design are conveniently handled by means of robust standard errors. All these corrections can have a sizeable impact on both point estimates and standard errors, and thus on which correlations are statistically significant. Differences in the results compared with previous research could thus be attributable to methodological artefacts.

Among our general results we can underline that:

1) We observe significant and relatively high correlations among all the values children aspire to for their own future. This probably reflects a general enthusiastic attitude in adolescents at this age towards their future. 
2) We observe significant and relatively high correlations among most values parents aspire to for their child's future, with only one exception: no correlation is observed between relationship values and materialistic values. Parents aspiring to their child being appreciated in the future because of money and power do not necessarily aspire to him or her being appreciated for tolerance and good manners.

3) Low correlations are observed between the values children aspire to for their own future and those which parents aspire to for their child's future. In fact, only materialistic values are significantly correlated between parents and children. Traditionally low correlations have been reported on current values of parents and children (Thomas \& Stankiewicz, 1974; Lawrence \& Valsiner, 1993; Gaskins, Miller \& Corsaro, 1992). In this study, the data refer to salient values aspired to for the future and the results reinforce the idea of adolescents as active agents, with their own personal aspirations for the future. Results suggest that only aspirations to be appreciated for having money and power may have a direct influence between parents and children.

When both parents answer together about the values they aspire to for their child's future we can imagine several different possible situations: (a) the two of them agree about the answer to be given; (b) they do not completely agree and they negotiate an answer, which typically should be the mean answer of the two different aspirations; (c) they disagree, but the aspirations of one of the parents have a major influence on the final answer given in the questionnaire and therefore the final answer should be equivalent to one parent's answer. In this study we ignore the extent to which both parents in each family agree or disagree in the values they aspire to for their child's future, and how in fact the answer to our questionnaire was given. However, none of these aspects seem to be particularly harmful to our research goals, because the factor invariance tests suggest that data of both groups are comparable. When factor invariance holds, multiple group SEM make it possible to see if different distributions of the data across groups are attributable to differences in measurement quality, differences in factor means or differences in factor correlations.

Some significant differences in factor means emerge between both groups. As regards correlations, they are broadly similar across groups in sign, size and pattern, with very few exceptions.

Several limitations of this study must be pointed out. First, a number of the conceptually relevant indicators have been lost in the process of statistical analysis. In future research new indicators or new ways of formulating the items in the questionnaires should be explored. Secondly, for reasons of sample size, the multiple group analysis could not be further subdivided into gender groups. Thirdly, all subjects in this sample belong to the same cultural context, and future replications would be needed in other contexts. Last but not least, our research is intended as a step forward, raising new questions from new evidence. However, it 
does not deal with one of the central relevant questions: what in fact are the psychosocial aspects that differ between one-parent and two-parent answering families which may explain some differences in the values socialisation process? Such problems need to be approached in future studies.

\section{References}

[1] Alwin, D. (1990): Historical changes in parental orientations to children. Sociological Studies of Child Development, 3, 65-86.

[2] Arminger, G. and Sobel, M.E. (1990): Pseudo maximum likelihood estimation of mean and covariance structures with missing data. Journal of the American Statistical Association, 85, 195-203.

[3] Bentler, P.M. (1990): Comparative fit indexes in structural modelling. Psychological Bulletin, 107, 238-246.

[4] Bollen, K.A. (1989): Structural Equations with Latent Variables. New York: Wiley.

[5] Bollen, K.A. and Long, J.S. (1993): Testing Structural Equation Models. Newbury Park, CA: Sage.

[6] Casas, F., Buxarrais, M.R., Figuer, C., González, M., Tey, A., Noguera, E., and Rodríguez, J.M. (2004): Los valores y su influencia en la satisfacción vital de los adolescentes entre los 12 y los 16 años: Estudio de algunos correlatos. Apuntes de Psicología, 22, 3-23.

[7] Casas, F., Coenders, G., Cummins, R.A., González, M., Figuer, C., and Malo, S. (2008): Does subjective wellbeing show a relationship between parents and their children? Journal of Happiness Studies, 9, 197-205.

[8] Casas, F., Figuer, C., González, M., and Coenders, G. (2004): Satisfaction with life domains and salient values for the future. Data from children and their parents in five different countries. In W. Glatzer, S. von Below and M. Stoffregen (Eds.): Challenges for Quality of Life in the Contemporary World. Advances in Quality-of-Life Studies, Theory and Research (pp. 233-247). Dordrecht: Kluwer.

[9] Casas, F., Figuer, C., González, M., and Malo, S. (2007): The values adolescents aspire to, their well-being and the values parents aspire to for their children. Social Indicators Research, 84, 271-290.

[10] Casas, F., González, M., Figuer, C., and Coenders, G. (2004): Subjective well-being, values and goal-achievement: the case of planned versus by chance searchers on the Internet. Social Indicators Research, 66, 123-141.

[11] Cheung, G.W. and Rensvold, R.B. (2002): Evaluating goodness-of-fit indexes for testing measurement invariance. Structural Equation Modelling, 9, 233255. 
[12] Coenders, G., Batista-Foguet, J.M., and Saris, W.E. (2005): Temas Avanzados en Modelos de Ecuaciones Estructurales. Madrid: La Muralla.

[13] Coenders, G., Casas, F., Figuer, C., and González, M. (2005): Relationships between parents' and children's values and overall life satisfaction. A comparison across countries. Social Indicators Research, 73, 141-177.

[14] Connell, R.W. (1972): Political socialization in the American family: the evidence re-examined. Public Opinion Quarterly, 36, 321-333.

[15] Del Río, P., Álvarez, A., and del Río, M. (2004): Pigmalión. Informe sobre el impacto de la televisión en la infancia. Madrid: Fundación Infancia y Aprendizaje.

[16] Gaskins, S., Miller, P.J., and Corsaro, W.A. (1992): Theoretical and methodological perspectives in the interpretative study of children. In W.A. Corsaro and P.J. Miller (Eds.), Interpretative approaches to children's socialization (pp. 5-23) S. Francisco: Jossey-Bass.

[17] Goodnow, J.J. (1994): Acceptable disagreement across generations. New Directions for Child Development, 66, 51-63.

[18] Hartrup, W.L. (1996): The company they keep: Friendship and their development significance. Child Development, 67, 1-13.

[19] Hess, R.D. and Torney, J.V. (1965): The development of basic attitudes and values toward government and citizenships during the elementary school years. Cooperative research project, $\mathrm{n}^{\circ}$ 1078. U.S. Office of Education.

[20] Jöreskog, K.G. (1971): Simultaneous factor analysis in several populations. Psychometrika, 36, 409-426.

[21] Kohn, M.L. (1983): On the transmission of values in the family: A preliminary reformulation. Research in Sociology of Education and Socialization, 4, 1-12.

[22] Kuczynski, L., Marshall, S., and Schell, K. (1997):Value socialization in a bidirectional context. In L. Kuczynski and J.E. Grusec (Eds.), Parenting and children's internalisation of values. A handbook of contemporary theory (pp. 23-50). New York: John Wiley.

[23] Lawrence, J. and Valsiner, J. (1993): Conceptual roots of internalization: From transmission to transformation. Human Development, 36, 150-167.

[24] Little, T.D. (1997): Mean and covariance structure (MACS) analyses of cross-cultural data: practical and theoretical issues. Multivariate Behavioural Research, 32, 53-76.

[25] Little, R.J.A. and Rubin D.B. (1987): Statistical Analysis with Missing Data. New York: Wiley.

[26] Little, R.J.A. and Rubin D.B. (1989): The analysis of social science data with missing values. Sociological Methods and Research, 18, 292-326.

[27] Meredith, W. (1993): Measurement invariance, factor analysis and factorial invariance. Psychometrika, 58, 525-543. 
[28] Mikelson, K.S. (2008): He said, she said: Comparing mother and father reports of father involvement. Journal of Marriage and Family, 70, 613-624.

[29] Muthén, L. K. and Muthén, B. (2004): Mplus. Statistical analysis with latent variables User's Guide. Los Angeles, CA: Muthén and Muthén.

[30] Muthén, B. and Satorra, A. (1995): Complex sample data in structural equation modelling. In P.V. Marsden (Ed.), Sociological Methodology 1995 (pp. 267-316). Washington, DC: American Sociological Association.

[31] Riordan, C.M. and Vandenberg, R.J. (1994): A central question in cross-cultural research: do employees of different cultures interpret work-related measures in an equivalent manner? Journal of Management, 20, 643-671.

[32] Rubin, D.B. (1977): Formalizing subjective notions about the effect of nonrespondents in sample surveys. Journal of the American Statistical Association, 72, 538-543.

[33] Rubin, D.B. (1987): Multiple Imputation for Nonresponse in Surveys. New York: Wiley.

[34] Rubin, D.B. (1996): Multiple imputation after 18+ years (with discussion). Journal of the American Statistical Association, 91, 473-489.

[35] Skolnick, A.S. (1988): The intimate environment: Exploring marriage and the family. Boston: Little, Brown.

[36] Thomas, L.E. and Stankiewicz, J. (1974): Family correlates of parent/child attitude congruence: is it time to throw in the towel? Psychological Reports, 34, 10-38.

[37] Yuan, K.-H., and Bentler, P.M. (2000): Three likelihood-based methods for mean and covariance structure analysis with nonnormal missing data. In M.E. Sobel and M.P. Becker (Eds.), Sociological Methodology 2000 (pp. 165-200). Washington, DC: American Sociological Association. 